\title{
BEING A GIRL GAMER - A Correspondence with Caitlin Martin V1.0
}

\section{Transforming Cultures eJ ournal, \\ Vol. 2 No 2, December 2007 \\ http:// epress.lib.uts.edu.au/journals/TfC}

\section{Subject: Being a Girl Gamer \\ Date: Sat, 5 May 2001 09:19:30 -0700 \\ From: Caitlin Martin \\ To: CYBERMIND@LISTSERV.AOL.COM}

I promised Jon I'd write about this for the book on gender online, so here's a first run at my thoughts. I thought it'd be good to put some ideas out there, see what they look like (may even discuss them) before writing something more formal \& thought out. Here goes:

I'm a girl gamer. We're not a terribly common breed. Games have mostly been the province of boys \& we've tended to wander in by accident. I never played D\&D in high school, although I knew boys who did, because that wasn't the kind of thing guys did with girls (not even girls they smoked a lot of dope with). I don't think it ever occurred to them to invite me \& it certainly never occurred to me to ask to be invited (much like it didn't occur to me at the time to start messing about w/computers). I satisfied my desire to play in the world of boys (always a strong one - the rebel in my likes to go where I'm told I don't quite belong - for better or worse) by drinking most of them under the table, smoking as much dope as they could, \& generally being as big (or bigger) hellraiser than they were.

I got into computers before I got into gaming. First via work (I fed myself for years as a secretary) \& then by plunging into the online world. Although I had some characters on standard MUDs \& wrote some monsters for the RPG part of a MOO, I didn't really MUD. It was boring to type hit whatever over \& over again \& I was a lot more interested in the interactions I was having with real people \& in exploring writing spaces than I was in living out some D\&D fantasy world. I wanted to explore how the 
net connected to my more or less real self \& play with the questions that got asked when we were all new online. I didn’t play earlier graphically based computer games because the graphics just weren’t sophisticated enough for me to be able to stand to look at them for the amount of time it would take to play a game. My computer was less a toy then $\&$ more a tool for feeding myself \& a window on who I might decide to reallyreally be. Later it became mostly a tool as I became one of those paid geeks. For about a year I stopped playing with my box at all - it was too much the tool I hammered away with every day for me to want to touch it.

Then I started dating the person I now live with \& he turned me onto gaming. He's an old-school D\&Der \& gamer \& he got me started originally because he thought it would be good for me to at least have some experience with something that he was going to continue to spend a lot of time doing. That time had been problematic with his previous girlfriend \& I suspect he wanted to try to forestall that with us. He didn't realize that I was perfectly content to curl up for hours with my book while he gamed. I decided to try out the game he suggested (Diablo) because it was something he loved to do \& I wanted to know a bit about it, plus I knew it would make him smile if I at least tried. I didn't expect to get hooked.

I've always been competitive \& aggressive as hell. I've also always been an only child \& a bit of loner (which meant no board games as a kid) as well as physically small \& kinda prone to indolent pleasure seeking which ruled out athletic prowess. I sucked at team sports \& didn't have much opportunity or inclination to do other sorts of athletic things. I competed, instead, academically \& musically (I played flute, went to a Fine Arts High School where I was first chair in the orchestra, competed at Festivals \& such). I played cards for awhile with friends in college \& was good at them, enjoyed the competition, but those things sort of fell away over time. In my 20's I started acting \& competed for roles \& then became a director \& competed for the ability to direct shows in assorted theatres, but I'd never really gamed. I played a little Doom \& some Duke Nukem, but my computer wasn't all that fast so it wasn’t much fun. My then computer made a great terminal, however, so I mostly MOOed \& e-mailed \& that was fine. I got out my aggressions online by arguing \& occasionally indulging in the sport of verbally humiliating the boy who just doesn't get it (my first taste of what it was like to fight 
back in a world where it didn't matter that I'm a lot smaller than everyone - I liked it, I'll admit, although I probably wasn't very nice).

My boyfriend went camping \& left me at his place to watch his cat with a copy of Diablo (the original game) installed on his computer. I started playing on a whim \& loved it. I got to run around with a great big sword \& kill things - lots of things. Better yet, I was good at it in a psychodeathteamer (my boyfriend's eventual nickname for me) kind of way. I liked the adrenalin rush of damned near dying \& running in time \& I liked the think fast on your feet strategizing. A lot of the girls I saw gaming tended to play archers or magic users/sorcerers, but not me. I discovered that I was at heart a melee fighter - none of that ranged weapon stuff for me, I wanted my danger immediate \& my response as direct as possible. I took the game home that weekend \& played through it with every character type (okay, I'm a little obsessive). My boyfriend's gamer boy friends kept saying, “Girls don’t game” \& had to shut up when I killed Diablo with a character type that none of them had been able to kill him with despite their penises.

I went from Diablo to playing various other games, although none of them quite suited me. It was hard to know what kinds of games to try out because I didn't have much experience as a player \& couldn't judge very well. I wasn't into puzzle-solving \& adventure games - too slow. I didn’t like strategy games, also too slow. I killed my party 3 times in Baldur's Gate because they were annoying \& was punished mightily by the game for it (games based on AD\&D rules are oddly old-fashioned about things like honor \& working with, rather than against, the group, as well as rewards for working toward the Good which didn't suit me). I did learn from playing AD\&D style games that my alignment is chaotic neutral which amuses my boyfriend (lawful good all the way) enormously since it's so reflective of all the things that make me fun (not to mention the things that make me difficult). I tried some first-person shooters, but ultimately found them too boring. I wanted to kill things, but I wanted more or a different environment. I guess I wanted less focus on my twitch response \& more focus on my ability to quickly come up with a strategy for killing things with a great big sword (axes are too slow to hit, although I do find the amount of damage they do appealing). 
Eventually I moved in with my boyfriend \& we networked our computers on his DSL line \& did a lot of gaming side-by-side. His gamer boy friends still found me a bit puzzling. They just couldn't seem to grasp the fact that I was a rabid as they were. Being a gamer girl helped in my work world, however, where I was surrounded by lots of geek boys who gamed \& thought a geek girl who gamed was pretty much the definition of heaven. They brought me games they thought I'd like \& included me in their conversations with great glee. Gaming cements my place in the working geek world where I am frequently the only woman. Most of the geek boys I've worked with have defaulted to treating me with respect \& honor \& a certain old-fashioned chivalry spiced with a certain amount of curiosity \& flirtation, but I didn't get to be one of the guys until I also became a gamer who could swing a sword with the best of them. It was nice to be accepted more fully into their world \& nice to have a topic of conversation to fall back on when starting new jobs (in my experience, geeks don’t talk much about baseball, but they do talk about computer games). It was also fun to run around in what was very much a boy's world with a female character who was just as (if not more) aggressive than they were. I particularly enjoyed violating their expectations. "So you play an Archer, right?” “Um, no, Barbarian Swordswinger, actually”.

At some point my boyfriend's gamer boyfriends decided they wanted to convince him to play Asheron's Call with them \& that the best way to get him to do that was to get me to play, too. So we did. As it happened, I quickly became as rabid about the game as the most rabid of them \& now have a 40th level character while my boyfriend isn't much into it \& frustrates them with his lack of interest. It was good for my relationship with them, though. I connected with his best friend, in particular, in a way I hadn't before. He'd always thought I was too pushy \& I reminded him too much of his ex-wife for comfort. I thought he was a judgmental asshole \& oughta loosen up. Playing AC gave us something neutral to talk about. He helped me out with some armor \& weapons, advice about character creation, \& was my superhero when I got myself in a tough spot \& needed help. He also discovered, however, that I played well, was very independent, \& could take care of myself in most situations. I didn’t mind dying \& would take on just about anything. I was interested in some of the same things about the game that he was interested in - game balance, character creation, strategy, PvP (Player vs. Player), whether it was okay to macro, etc. I had enough background from my MUDD/MOO days to have a perspective on online community that was new to him since Asheron's 
Call (a Massively Multi-Player Online Role Playing Game or MMORPG) was only his second experience with online gamer/geek communities (he played Ultima Online first). A lot of the issues that come up in MMORPG's were argued over \& hashed out on MUDs (\& frequently solved more successfully) so they weren't new to me \& my perspective was somewhat unique. From there we started talking books \& politics \& passing dirty jokes via e-mail \& these days we're friends.

It's interesting to be a woman playing a female character on Asheron's Call. For one thing, although a fair amount of women play, most of the female characters you see are boys who are gender bending to take advantage of some of the goodies you get for being a girl. At early levels random boys tended to come up to me \& give me armor or weapons or offer to take me hunting or show me dungeons - they liked the idea of showing me the ropes plus I was a girl \& that seemed cool. Things changed as I leveled. Around level 25 I started taking kills from boys in tougher dungeons \& they didn't like that too much. I suddenly became in many ways persona non grata. They didn't chat much, \& some were actively hostile. I’ve had more than one "train" of monsters run down on me by some boy who didn't want me playing in the same dungeon. I think the fact that I played a swordfighter rather than a support mage caused me difficulty as well. They just didn't know what to do with me now that I didn't really need their help. I learned to solo a lot \& learned to suck it up \& cope when I died somewhere scary \& had to get my body back without help. Sometimes that really sucked ( \& consequently I just about always help with body retrieval if I can), but I still had a great time. I liked being able to take on a room full of monsters \& kill just as many \& fight just as hard as the boys. I liked violating their expectations of what or how I should play \& liked being able to rescue a few of them when they got in over their heads. It frustrated me when they ignored me, but frustrated me more when they jumped in to "rescue" me \& consequently stole my XP (experience points) \& kills, but that made me work harder to play better \& get better equipment so they couldn’t easily outdo me.

At 40th level boys talk to me \& hunt with me again, but they assume I'm male until I tell them otherwise. It's mildly annoying that they assume I'm a guy because of my character type, level, equipment, ability, but funny to see them dealing with my gender when I let them know I'm a woman. Some of them start trying to take care of me in ways that inevitably get them killed when they learn my gender (I suppose it's that 
weird chivalry thing again). Some of them don't care, they're just glad to have another good player along. Some of the lower level boys ask me for advice on where to hunt although some also demand buffs (spells that tweak a player's statistics) or money for armor \& are very annoyed when I don't comply (thank you is a key phrase if you want me to go out of my way for you). Lots of them want to know if I have a boyfriend \& are envious of him for having a girlfriend who never hassles him about the time he spends gaming. Most of those boys have partners who resent the large amounts of time they spend playing on the computer instead of doing things with them. I can relate, actually. I'd hate it if my partner wasn't a gamer at this point because it's something I really enjoy doing \& probably won't stop doing any time soon. Some of them are sort of stunned \& confess they never met a girl who played games \& definitely never met one who could rescue them from a group of monsters when they yelled for help in a dungeon.

For me, gaming is another way for me to play with the boy's toys I was told I couldn't play with when I was growing up. I've always resented being shuffled off to play hopscotch or jacks when I really wanted to jump out of trees \& play cowboys \& Indians. It's a good place to work off my aggressions, intellectually challenging without being draining, \& competitive in the ways I like. It's nice being able to be "physical” \& violent \& as tough as the men I play with even though most of them could overpower me physically in real life. Mostly it’s just a lot of fun.

It's odd, though. Women don't game much \&, although there are some famous exceptions \& a few web sites, for the most part girl gamers don't seem to bond \& congregate (although maybe I'm going to the wrong places). It seems like an oddly solo activity for the women I run across when I'm gaming despite the attention you're guaranteed to receive from certain gamer boys. There's been some writing done about gender in games \& some women have played with ideas in this arena, but a lot of it has been directed towards the first person shooters which are a very different beast. Girl gamers seem to put up with typically big breasted nearly naked female avatars (if they get to play a female avatar, at all). One of the most amusing times I've had gaming with my boyfriend was killing Diablo together in Diablo 2 - me as a big male Barbarian, him as a delicate female sorceress. I suspect that one of the reasons AC seems to have a fair number of female players is the ability to play any character type as a female without 
having to wander around looking like some developer's wet dream. Female avatars in AC look like girls, but they look like real girls \& wear the same armor \& so forth as the guys \& that's a really nice change. The game also doesn't apply penalties to stats (strength, for instance) based on gender. It might be more realistic if it did, but I'm not playing games for realism - they’re good escape \& I want them to stay that way.

I'm glad my boyfriend opened the door into this world for me. It's a whole lot of fun, a great stress reliever (bad day at work - go home \& kill things), something cool to do together, \& also something I wouldn't have thought to try on my own. It satisfies me on lots of different levels in a way nothing else has \& it's a much cheaper addiction than many others I could have acquired. Plus I’ll never be without a date again. Heh.

c.

\section{Subject: Re: Being a Girl Gamer \\ Date: Sat, 5 May 2001 11:59:10 -0700 \\ From: Caitlin Martin \\ To: CYBERMIND@LISTSERV.AOL.COM}

On Sat, 5 May 2001, ana murmured:

$>$ It was really odd to read your letter, Caitlin! I recognized myself in many

$>$ aspects of your description. I play Everquest and have a level 50 char on the

$>$ game, but I had played all kind of games, online and on the computer. I played

$>$ the Ultima series and I followed the series when it became an online game. To me the

$>$ attractiveness of the games was the epical structure of the story, much related to

$>$ the romans from the Celtic and French Middle Ages, "Chanson de Roland",

> "Arthur's Death" and so on. I am myself an anthropologist and a writer and

$>$ felt myself tempted to use my writers and my anthropological skills to "judge"

$>$ the games and make game analysis.

That's really cool. I'm always glad to hear of more of us out there. I haven't played Everquest, primarily because it's a game that in the higher levels tends to force you to group with other players \& I'm too cranky to want to depend on other people for play. AC allows for grouping, but also leaves lots of room for solo play which suits my style better. UO (Ultima Online) made me impatient. A lot of the problem issues there 
(rampant \& out of character PKing [Player Killing, or killing player characters] for one) were issues I'd seen dealt w/more effectively on MUDs \& I just couldn't get into the game enough to deal with some of the headaches (much as I wanted to). The problem, of course, with policing a lot of this stuff in the newer \& larger MMORPGs is sheer size. MUDs \& MOOs were much smaller which made it more possible for the community to police standards of behavior, plus everybody knew the wizards were God, the MUD/MOO universe was fascist, so out of control folks just got their butts ignored or booted. The newer games are so large it's more difficult for the players themselves to develop \& police community standards, plus people are paying for them so I suspect that the gaming companies are reluctant to be as draconian as most MUD/MOO wizards could be. Unfortunately, that leaves the ongoing problems of exploits, random PKing of other players, etc. as ones still to be solved \&, in the meantime, it's too easy to get hassled by bored 12 year olds. ;>

$>$ I write computer games reviews in the largest of Sweden's daily papers and I

$>$ am the only "grown up" reviewer who looks at the games with a mixture of

$>$ fascination and critical gaze.

That's also very cool. I think that MUDs \& MOOs had a real advantage over MMORPGs in this area since they were textual (analysis more obvious) \&, again, much smaller communities with a much more serious role playing tradition. On the other hand, I love the sheer geographic sprawl of games like Asheron's Call \& graphics are nice in their own way. It's going to be interesting to me to watch how things turn out in these games as they begin to grow up. I think it's good for the gaming community to get a different kind of reviewer, if only because people tend to get hidebound in their own ideas \& need new voices to help keep things interesting.

$>$ I am 47 years old, definitely to old to compete with my "co-gamers" at

$>$ Everquest, but I feel, as you, a strange satisfaction in break the rules. I

$>$ feel the gaming is an androgynous skill. Have you read Johannes Huizinga "Homo

$>$ Ludens”, one of the best books written on the play subject?

$>$ I enjoyed very much your letter, keep playing!

$>$

Heh. Yeah, I'm 38 \& don't have unlimited hours to play, but I'm still having a great time \& yeah -- it's cool to break the rules. How do you mean an androgynous skill? \& now, I haven't read that, but I'll definitely look for it. No worries about me continuing 
to play. Among other things I got in the beta test for the Diablo 2 expansion pack \& am shortly returning to my newly acquired skill of turning into a werebear (so so cool).

;>

C.

\section{Subject: Re: Being a Girl Gamer}

Date: Sat, 26 May 2001 02:04:24 -0700

From: Caitlin Martin

To: CYBERMIND@LISTSERV.AOL.COM

On Wed, 2 May 2001, Jon Marshall murmured:

$>$ Thanks for all this Caitlin, its interesting autobiography, something

$>$ that helps us situate events.

$>$

$>$ just a few questions...

$>$

Thanks, Jon. Sorry it's taken so long to get back to this. I'm job hunting, atm, \& using most of my computer time to either do that (or escape from doing that). Anyway, here goes:

$>$ I'm not a computer game player to any extent, so please put up with me.

$>$ How does this early dislike of hacking and slashing, and wanting to

$>$ interact with others, connect up with your current experience, which

$>$ seems to be almost the other way round?

$>$

That's a really interesting question \& I hadn't thought about it until you asked it, in fact. I was never really into MUDD-style of hack \& slash mostly because I could think of things I'd rather do in a text-based world than type hit monster over \& over. On MOOs \& MUDDs I was involved with the RPG aspect of things more as a builder. I built a lot of MOO \& MUDD environments \& also wrote dialogue messages \& monster messages \& descriptions for friends who were programming MUDDs \& the RPG portions of assorted MOOs. I played some, but mostly either wrote places or wrote bodies for 
myself, argued MOO.politics (on LambdaMOO) or had theoretical/philosophical discussions about virtual life (on DhalgrenMOO), \& talked to people.

With MMORPGs, which are essentially graphical MUDDs, it's different for me. The experience is more visual, the communities are so large as to be fairly unwieldy in terms of making a name for yourself in the way you could on MOOs. I suspect a lot of it is that words aren’t as primary as well as that you can’t change or interact or develop the environment in the same way that you could on MUDDs \& MOOs. It's all pretty much pre-scripted/pre-designed/pre-programmed. You can play within someone else's environment, but aside from avatar personalization \& some individual character customization in terms of skills \& attributes you don't get to change the world. I can't $\log$ into AC \& build a quest or a new place, although I will be able to do that in Neverwinter Nights which should be really cool.

I think the social aspect is less important to me because my life is pretty different now than it was a number of years ago. I'm more established with people of like mind who live here in S.... than I was when I first came online, so the social aspects of it all are less important. I also got really burned out on the social aspect of MOOing. I had 3 different lovers that I met on the MOO \& lots of friends who I also saw in RL, traveling to assorted MOOBashes \& other events. I also knew a lot of MOOers because I was active on LambdaMOO's mailing lists (particularly the now-defunt *social-issues) \& was later on the Architecture Review Board. I'd reached a point where the noise for me online was too much. I also felt that I was becoming increasingly sucked into this incestuous little world \& I wanted some quiet \& a break from it.

There's a social aspect to the gaming I do now, though - definitely. I game either with or in the same room as my boyfriend/partner. A number of our friends are also gamers \& we play some games together. There's also the aspect of always having something to talk about at work that I mentioned in my post (heh) - something that isn't football, that is. My boyfriend \& myself \& some of his gamer boy friends are planning to play Dark Ages of Camelot together when it comes out. They're all guys he's played pen \& paper D\&D with for years who've accepted me in their online gaming adventures - mostly, I suspect, because I'm as rabid a gamer as the worst of them \& also a very effective 
melee fighter. We're planning to settle in Midgard \& I'm gonna play a female Viking berserker which should be fun.

I suspect that I'll probably play Neverwinter Nights less than I write for it (since that's a possibility). My boyfriend \& I plan to host a server \& to write content for the game which should be a lot of fun. I guess if I can create/build I'm prone to do that, but if I can’t I've become okay with just killing lots of stuff. ;>

I think the Net brought home to me the idea of life as storytelling \& of the games we all play with masks. Doing theatre (acting \& directing) had started me thinking about this, as had reading Thomas Kuhn in college (oddly enough), but the Net made the transient nature of personality or personhood or reality (or whatever you want to call it) much clearer to me. I was suddenly very much in a place where everyone you met was in one or another inventing a self or selves \& some of us were talking about it, as well. It was all very curious in the beginning - living a life that was one foot in the physical world \& one foot in the virtual (almost purely textual) world. There weren't many of us, \& our family \& friends tended to look oddly at us. A lot of people thought they could separate themselves from their meat in this place, although I was never one of those people. At heart I suspect I'm too much of a sensualist to ever want to rid myself of the physical. Words are very physical to me - they have sound \& shape, of course, but also taste \& smell \& feel \& color \& so forth, in my head they do anyway. There were all kinds of interesting essentially political questions being asked \& discussed, as well, as more women came online \& began to interact in a world that had been almost exclusively male. This was particularly true on MUDDs \& MOOs which had been populated primarily by male computer scientists with a few women. At the time I came online both sorts of communities experienced an influx of women who weren't computer scientists or engineers or even anybody's girlfriend. Many were artists of one kind or another or academicians or students \& we things changed after our arrival. Some of these non-computer types who came online were also male \& I think it was probably just as difficult for the old-style folks to interact with them as it was to get used to us.

There were gender clashes on mailing lists, as well. Women got more involved \&, when they got flamed, for the most part had issues with the perceived male-dominated language of many lists \& flamewars. Some of us, on the other hand, found that our 
language fit better in these places, discovered the competitive \& aggressive joy of writing a good flame or winning a mailing.list argument. I've always been much more direct than most of the women I've known \& for me these spaces were very comfortable - more comfortable than trying to interact with my at-the-time secretarial co-workers who tended to look askance at me when I didn't pussyfoot around things. A part of me loves a good flamewar because it's an arena I'm able to be competitive \& aggressive in without regard to my stature or gender. I'm smart, write well, \& enjoy the turn of a good phrase enormously \& that's what counts in a good flamewar. When I say a good flamewar I mean one in which real argumentation occurs along with creative skewering as opposed to the kind of flamewar where everyone basically types YOU'RE WRONG in all caps.

On LambdaMOO we were asking the question: can a virtual society run as a democracy? \& discovering that for most virtual communities fascism is the way to go. My server, my mailing list, my MOO, my programming time, my admin time - my way or the highway. This was an interesting discovery \& troubling, as well, to those of us who considered ourselves good left wingers \& promoters of freedom for all. Heh. Offline I'm still that, but online I'm an unrepentant fascist. I'm not sure I've completely resolved the contradictions there yet, but maybe I don't need to at this point. Some things you just accept as they are.

Then there were the questions about what it might mean to develop deep \& intimate relationships with people you'd never met. What did it mean to fall in love with someone's words on a screen? What does the fact that this happens say about the nature of love? This is not to mention all the questions that arise from net.fucking -- what does it mean to experience real physical desire \& even orgasm from text on a screen? \& soon enough we all started learning what it meant to translate these relationships into relationships that spilled over into real life as more \& more of us met in the flesh. I've met more MOOers than I have people from my mail lists, but know the oddity of fleshmeets. There's this funny instant where the idea you have in your head of a person from your online interaction with them \& their actual physical reality have a battle with each other for primacy \& then, somehow, the two forms (if you will) coalesce. After you meet in the flesh, however, it's all different. Neither real life interaction nor virtual interaction is ever the same \&, in my case, it's typically the virtual interaction that lost 
out. A is actually the only e-mail list person I've ever met (\& that briefly) in the flesh \& I know our relationship is different now than it was before we met. In our case, I think we're more comfortable \& easily intimate with each other than we were before. A \& I have owned this list together for a number of years now \& sometimes go months w/out talking, but I always feel him out there \& we connect at wonderfully odd synchronous moments. Sometimes it feels like we're an old married couple that lives far apart by choice, but still connects in all the old ways when the occasion merits - Sarte \& Simone de Beauvoir, perhaps, although the relationship is definitely less toxic.

For me personally, the big questions had to do with who I wanted to be having trashed my whole life \& begun from scratch. MOOing was, in fact, a big part of my trashing my life. I got divorced while online \& a lot of the courage I needed to end my marriage was a direct result of my online experiences. The vast majority of the emotional support I got, as well, came from folks I knew online who were always incredibly giving \& dependable in ways that still amaze me. My first lover after my marriage broke up was a (much younger) fellow MOOer \& the person I next fell in love with was yet another fellow MOOer who drove 1300 miles on a long weekend just to meet me because he thought my words were amazing (one of the most romantic things that ever happened to me, particularly since I hadn't even said he could sleep on my couch much less become my lover). I used these stages to reinvent myself - still do, I guess. The person I am now is the person I imagined I'd like to be when I became a MOOer. The life I lead now is a direct result of that experience - from my career (I became a support engineer/sysadmin \& started making a lot more money than I ever had) to having my writing published (thank you, A - my biggest \& most helpful fan) to having the confidence to just be myself \& stop trying to be who I thought I ought to be. Being online \& the acceptance I found here helped to birth me.

$>$ If i may digress into offline Roll playing memorabilia. I

$>$ remember that in a game I was running a woman refused to play any

$>$ character type other than a healer and not get involved with the

$>$ violence. However, by chance she was chosen by a magical sword, which

$>$ teleported her into the middle of combat and such. Eventually she became

$>$ as gung ho as the sword could wish, and ended up founding her own combat

$>$ oriented religion with herself in charge :) (This was Runequest II)

$>$

$>$ I'm wondering how many people have noted a tendency of female gamers to

$>$ fight from the back lines? I not so sure it happens in offline RPG, but

$>$ that might be because in the fantasy games I've played beginners usually 
$>$ are told to play a fighter as it's simpler and requires less rule

$>$ knowledge, thus everyone gets some experience of this almost

$>$ immediately.

$>$

In my experience, women tend to play ranged fighters or support mode characters. Women who play pure melee fighters are much more rare, particularly at higher levels. I see lots of female high level life mages (who heal \& cast protects \& buffs) \& archers on AC above level 40 \& very few female sword or ax fighters. As I said in my previous post, once I hit level 40 male players just assume I’m a guy \& usually call me “dude” or refer to me as “he” even after they've been told otherwise. I know there have to be more women out there playing melees, but I don't seem to run across them. I've never had much interest in playing a support character \& play archers \& spellcasters \& other ranged fighters relatively poorly. As a friend says, "I like my killing direct \& hands on." I don't, actually, think it's easier to play fighters - at least not at higher levels. There's too much of melee fighting that requires quick tactical decisionmaking (not to mention the sheer bravado or steely nerves or just pure love of adrenalin it takes to get down to 4 hit points before the battle's won).

I suspect women have tended to choose support characters because, in general, women are taught that supporting others is our place in life. We're encouraged to be caretakers \& team players \& to let the other guy win \& discouraged from what are usually considered more male kinds of risk-taking, selfishness, \& competitiveness. I think this may be less true for women younger than me (I'm 38), but the cultural expectations are still there \& still difficult to surmount. Gaming is one place you can be an aggressive woman $\&$ be pretty much guaranteed some level of positive attention from the guys who play with you. For instance, in the real world I have a long history of difficulty with interaction with other women. I just do better with men. As I said, some of that is how direct I am, some of it is just that I've always been more interested in the things the boys/men I've known were interested in. If I have a job interview \& the manager is female, I won't get the job. If the customer is female, she'll take offense to something I say or the way I say things \& is likely to both argue with me about my expertise \& complain to my manager about my customer service. If I interview with a male manager, I get a job offer. If the customer is male, they may argue with my expertise, but usually I win them over \& they almost always write to my manager about how 
wonderful my customer service skills are. I don't know if this is related to why I play melee fighters, but I suspect it could be.

$>$ Just an aside, and i'm wondering if its just my friends, but in every

$>$ game i've ever played it was almost always impossible to distinguish the

$>$ lawful good types from the lawful evil - they always ended up killing

$>$ people on principle in huge quantities. But then this seems to be a

$>$ feature of the world as well :)

Heh. I tend to agree, but that's why I'm chaotic neutral - or so I'm told. My boyfriend \& most of his friends are pretty purely lawful good \& tend to be shocked when the chaotic neutral among us do things like kill all the guards to get a quest done while they're trying to negotiate. I'm not sure it's nicer to kill everybody in the name of expedience than it is to kill in the name of principle, but it's different, anyway. I'm told most D\&Ders like at least one chaotic type in the group if only for the entertainment/shock value. ;>

$>$ what is the kind of interface these games have if they are not somehow

$>$ similar to first person shooters?

It's not so much interface as orientation. First person shooters tend to be all about killing everything that moves. RPGs can be about that, but also tend to be more adventure/quest-oriented \& to have a relatively deep backstory or mythology that governs play. I tend to like to kill everything, but in pursuit of some quest or the solution to some in-game mystery. I still kill everything, but I get to tell myself a cool story about it all. I've never managed that in first person shooters which always seem to be more about the efficiency of my twitch response than anything. I did like Duke Nukem a lot, but it was a bit weird as first person shooters go with lots of ironic parody in-game. Still, playing that game I spent most of my time perfecting moves. In games like Diablo or AC I'm perfecting moves, but I'm also interacting with the story \& the world \& developing my character within the contexts that get thrown at me.

I may feel differently about this in a few weeks. Since I'm out of work at the moment, I'm planning to install Alice (a first person shooter based on a mad Alice in a demented Wonderland) \& play through it. I'll let you know how it goes. 
One other difference in first person shooters is the prevalence of cheat codes \& god mode abilities which render the player indestructible \& are very very hard not to use once you know about them or how to find them. There are exploits in MMORPGs, but they're somewhat different \& don't usually enable one to become indestructible in the same way. I'm likely to cheat in first person shooters \& unlikely to take the trouble in MMORPGs. The reasons for this have to do with the fact that the first person shooters I've played have been single player so my cheat isn't impacting anyone, but me. In MMORPGs I don't cheat because I think cheats \& exploits in multiplayer games have a negative impact on the community \& I'm not interested in being that sort of grief player.

$>$ This is your current kind of work with computers?

$>$ I think that it is possible that some kind of time frame might be useful

$>$ in following your account

I'm currently out of work, but am probably going to get an offer from a Web hosting company I'm interviewing with (last interview next week). My most recent job was as a Support Engineer for a software company (not a good fit), but before that I did escalated troubleshooting \& was a sysadmin for an Internet Service Provider. One of the reasons I'm hoping for the job with what is essentially a server farm is that it'll put me back in the world of network.geeks who are pretty different than software-oriented geeks, particularly the network.geeks of the Unix denomination or flavor. I love the complexities \& weirdnesses of networking \& plan to get Cisco-certified because I want to get deeper into routing from a hardware perspective. I've been a DNS administrator \& consequently have a strong understanding of networking \& TCP/IP from more of a software perspective \& I want to know more about translating the principles into hardware. Routers are fun toys. ;> My big \& not-so-secret dream is, however, to eventually work my way into content editing for a gaming company \& I hope to get there, but in the meantime networking is a good way to pay the bills \& even have money left over.

$>$ does it also make doing the work easier? or collaborating with others at $>$ work easier?

Both. That I'm a gamer \& am as good at \& as enthusiastic about the games my male coworkers play gets me over a lot of the humps I tend to encounter because I'm 
frequently the only woman who does the same job they do \& often the only woman they know who's into computers. It helps make me "one of the guys" which makes it easier for me to get the respect I need to do my job (\& deserve). I don't have to prove myself quite as much. I'm still a girl, mind you, but I become "their girl” \& things just get easier over all. Collaboration is easier \& many of them are lot more eager to share their knowledge with me (they know I'm actually listening \& interested - typically unlike their girlfriends, sadly) \& to share my knowledge with them. Bypasses the hazing, if you will.

$>$ why is he so uninterested? and why do you find it so engrossing? Is it $>$ simply the connection with his friends?

I'm not entirely sure why he's so uninterested with the game. I think it's primarily that it's a game that you have to devote a lot of time to in order to succeed \& he likes to jump around from game-to-game. Since he tends to play several games at a time, he’s never gotten an AC character to a level as high as mine \& nowhere near the levels of his friends \& so it's difficult to really play in a group. He's too underpowered \& they're too overpowered \& everybody ends up pissing everybody else off. He’s also impatient with the way that Turbine/Microsoft (AC’s developer \& publisher respectively) don't enforce their Code of Conduct \& tend to create an atmosphere where exploits \& in general annoying behavior can proliferate. I turn most of that off with little effort, but he's not as good at tuning other people out as I am. I got engrossed in the game because it's the closest thing to MUDDing/MOOing I've come to w/out having to start up MUDDing \& MOOing again. Although it's graphical \& I can't create in the way I could in MUDDs \& MOOs, it still has the feel of a MUDD \& that's something I've found I've missed. I'm irritated, in general, with the ways that the games tend to be run (which seem too permissive of behavior that spoils other people's good time) - most of the problems I see in these games were solved on MUDDs years ago - but I'm also amused \& tend to ignore things that irritate me that I know I can't change. I guess I'm sanguine about being on somebody else's server \& dealing with things their way. I don't play with his friends very often, but I do chat with them a lot about the game \& one of them has been really generous with armor \& whatnot for me \& impressed with my gaming ability \& rabidness.

$>$ What is a Macro in a game? 
What I view as a truly stupid activity which is setting up your computer to do certain activities for you so that you level up your character without actually playing. In AC, for instance, most of the better content is for higher level characters (or that's the impression a lot of people have, anyway) so lots of people macro characters up to higher levels before they actually play. I think it's amazingly stupid to have your computer play your game for you \& also impractical in terms of survival once you do play the character. Part of leveling up a character is learning how not to die. Macroing was generally outlawed on most of the MUDDs I played \& is outlawed in Ultima Online, as well (I dunno about Everquest). I also think it's a huge waste of server resources \& know it contributes to lag which is unmannerly behavior in my opinion. It's one thing for the server to lag because lots of people are actually playing \& another for it to lag because lots of people are watching TV while their computers play. Lots of folks will argue with me about this \& there's a wide range of opinion, but that's mine.

\section{$>$ Can you say more about Ultima online?}

I was in the beta test for the game, but never really got into it. The graphics weren't good enough for it to be as interesting to me as the text-based worlds I was playing in \& it got too quickly populated with k3wl d00dz who weren't role players. MUDDers \& MOOers tend to be dedicated role players. Lots of the UO folks were mostly interested in running around \& killing other players \& generally being a pain in the ass. AC solves this problem by having a dedicated PK (player-killer) server with the rest of the servers being “carebear” servers (non-PK). I play on a carebear server so I don't have to deal with 13-year-olds killing me every 5 minutes. I don't play on the AC PK server because it's just about impossible due to the number of folks hanging around killing newbies. I've played on MUDDs that are PK, but there are typically consequences for killing other players unless the killing is done within the roleplaying context of the game \& enforcement tends to be pretty good. So far, MMORPGs haven't solved this problem. For one thing they're bigger which makes community policing more difficult \& for another everybody's paying to play which people tend to think allows them to behave however they want. My hope is that developers will get over thinking that \& think, instead, of their responsibility to maintain a game where everyone is more able to have fun. 
Dark Ages of Camelot will be PK, but only within the context of wars between realms. You won't be allowed to PK other players within your own realm \& I have hopes for this solution. The game is being developed by some folks who run a text-based MUDD \& I think they may have a better handle on some of the issues (like PKing \& enforcement of Codes of Conduct, etc.). It'll be interesting to see, anyway. Certainly everything I've read about the game has the feel of a MUDD, more so than AC, \& that's got a big appeal to me. I'd like to get more involved in that community, although I still want to be able to solo play. Everquest, for instance, encourages more community involvement, but that happens at the expense of your ability to solo play. Past a certain point, Everquest pretty much requires that you play with a group \& I don't want to have to do that all the time. AC's much better for solo play, but doesn't do enough to encourage community happening so it mostly doesn't. We'll so how the new game does with all this. Again, I’ll keep you posted.

$>$ What kind of issues here?

As I said, above, mostly issues related to mannerly behavior - exploits, random player killing, etc. On a MUDD or MOO any behavior that impacts the ability of other players to play the game is unmannerly \& subject to assorted penalties, including banishment. There are also issues related to sexual harassment in these games, although I've had less trouble on AC than I had on MUDDs \& MOOs. I've been hassled somewhat, but not nearly to the degree I've been hassled in the text-based communities. I probably deal with it all better since I’ve got more experience, as well. I, for instance, don't hesitate to squelch annoying players where some women I know resent having to do that \& try to either change the other player's behavior or make someone in authority change their behavior. I don't have any faith in anybody’s ability to change the behavior of assholes (cynic that I am) so I just squelch 'em \& wish I could do it in real life.

I probably take words more seriously than I do graphically based activities \& tend to be more intellectual about them. It's a lot like the difference between radio \& TV - MOOs are more like radio \& allow me to engage more of my imagination, MMORPGs are more like TV \& engage the part of my brain that wants to escape \& turn off. I definitely think \& strategize in the games I play, but it feels less intellectual than the thinking I did when I was MOOing regularly. 
cheers, c. --

$* * * * * * * * * * * * * * *$

\section{Subject: Bit More on Grrl Gamers \\ Date: Sat, 26 May 2001 03:15:18 -0700 \\ From: Caitlin Martin \\ To: CYBERMIND@LISTSERV.AOL.COM}

I put together a small survey \& posted on the Asheron's Call boards for other female gamers who might be interested in answering some questions. I'm focusing on AC players since I'm primarily interested in comparing my experience with that of other women playing the same game. I've asked that they be female in real life although their AC characters don't have to be. I may decide to talk to male gender benders at some point, but for now I want to talk to other women. There is, of course, no way to tell if the people who respond are female, but I'm gonna trust my instinct about gender \& assume that most people won't bother to lie all the way through a survey \& leave it at that. I'll let y'all know what I find out once I've finished - I figure a couple of weeks from now. I'm hoping to get answers from women both older \& younger than me since I suspect that the experience is different if you grew up at different times. My prediction is that younger women will have had an easier time getting into gaming \& will play a wider assortment of character types, but since I don't know that for sure it's worth it to ask. I'm not gonna drudge up my eons-ago anthro grad school training \& even attempt a “scientifically valid” survey so results won't mean much statistically, but then one of the reasons I left grad school was cuz I thought 2 stories were worth as much as 5,000 carefully statistically balanced \& collated answer sheets any day of the week.

cheers, c. 
Interestingly, just requesting that women fill out a survey has been a lesson in gender interaction. When the post was on the boards, a bunch of male players appended their own posts to my request, all giving me the lowdown on female gamers. Heh. Since the request hit the news portion of the site, I've gotten 7 e-mails from men telling me how women game, telling me how to design my survey, etc. 6 men have volunteered wives or girlfriends to answer the survey (without talking to the women first). 1 man volunteered his female monarch in a similar way (in AC there is an allegience system \& monarchies can be very small or quite large). 1 man sent an e-mail on behalf of his girlfriend saying that they'd read the post on the Web site \& she'd be interested in “filling out your little survey”. Amazing.

[[Sadly no more was heard, and Caitlin disappeared]] 